\title{
Chromatic stability of acrylic resins of artificial eyes submitted to accelerated aging and polishing
}

\author{
Marcelo Coelho GOIATO', Daniela Micheline dos SANTOS ${ }^{1}$, Josiene Firmino SOUZA², \\ Amália MORENO ${ }^{3}$, Aldiéris Alves PESQUEIRA ${ }^{3}$
}

\begin{abstract}
1- DDS, MSc, PhD, Professor, Department of Dental Materials and Prosthodontics, Araçatuba Dental School, São Paulo State University, Araçatuba, SP, Brazil. 2-DDS, Undergraduate student, Department of Dental Materials and Prosthodontics, Araçatuba Dental School, São Paulo State University, Araçatuba, SP, Brazil. 3- DDS, MSc, Graduate student, Department of Dental Materials and Prosthodontics, Araçatuba Dental School, São Paulo State University, Araçatuba, SP, Brazil.

Corresponding address: Marcelo Coelho Goiato - Rua José Bonifácio 1193 - Vila Mendonça - Araçatuba, SP - Brasil - 16015-050 - Phone: 55-18-36363287 - e-mail: goiato@foa.unesp.br
\end{abstract}

Received: May 18, 2009 - Modification: April 05, 2010 - Accepted: May 21, 2010

\section{ABSTRACT}

Esthetics and durability of materials used to fabricate artificial eyes has been an important
remaining tissues and help with patients' psychological therapy. However, these materials
are submitted to degrading effects of environmental agents on the physical properties of
the acrylic resin. Objective: This study assessed the color stability of acrylic resins used
to fabricate sclera in three basic shades (N1, N2 and N3) when subjected to accelerated
aging, mechanical and chemical polishing. Material and Methods: Specimens of each
resin were fabricated and submitted to mechanical and chemical polishing. Chromatic
analysis was performed before and after accelerated aging through ultraviolet reflection
spectrophotometry. Results: All specimens revealed color alteration following polishing
and accelerated aging. The resins presented statistically significant chromatic alteration
(p<0.01) between the periods of 252 and 1008 h. Conclusions: Both polishing methods
presented no significant difference between the values of color derivatives of resins.

Key words: Color. Resins. Dental polishing. Ocular prosthesis.

\section{INTRODUCTION}

Maxillofacial prosthesis is a specialty with the basic goal of restoring esthetics and function, protecting the remaining tissues, and helping in psychological therapy ${ }^{15}$. Among the various modalities of this type of prosthesis, the artificial eye is outstanding; although it does not restore primordial function, that is sight, to the wearer, it satisfactorily restores its facial esthetics. Furthermore, the artificial eye is responsible for the individual's reintegration into society, returning a condition of comfort to the user as regards its social intercourse and acceptance of the deformity, thus improving patient's quality of life ${ }^{16,23}$.

Concern about esthetics and durability of the materials used for fabricating artificial eyes has encouraged studies over the course of time ${ }^{9-12,29}$. One of the most worrying aspects in treatments with artificial eyes is that they become disagreeable after a few months of use, and it becomes necessary to have them redone due to color instability and decreased resistance as a result of the effects of ultraviolet rays, deposition of microscopic residues on the surface porosities, continual handling and cleaning of the prosthesis by patients s, $^{8,15}$.

It is known that color stability is the property a material has of retaining color for a period of time in a certain environment, and is an important physical property of many dentistry materials ${ }^{2}$.

Shade determination in Dentistry can be divided into two categories: visual and instrumental. Instrumental colorimetry potentially tends to eliminate subjective errors in color assessment. This type of analysis is more exact than measurement by the naked eye, because it is capable of assessing small difference in the coloring of objects ${ }^{5,6}$.

One aspect hardly mentioned by professionals in the area is the chromatic stability of these resins when submitted to different polishing methods. Clinically, polishing of artificial eyes is a factor of the utmost importance, as they must present a smooth surface, otherwise the presence of roughness favors the accumulation of impurities and bacteria, 
irritating the patient's anophthalmic cavity, an in addition discomfort, also causes infections ${ }^{15}$.

Conventional polishing of acrylic resins is performed in stages, in a bench lathe, and any negligence in any one of the stages of the procedure, makes the subsequent polishing stages more difficult ${ }^{32}$. In relation to chemical polishing, this was described as an alternative technique to decrease water absorption of resins. According to this technique, the polymerized resin is immersed in monomer heated to boiling point, for 1 minute, which results in well polished internal and external surfaces ${ }^{18,27}$.

Based on a literature review, and considering the degrading effects of environmental agents on the physical properties of the acrylic resin, this study assessed the color stability of acrylic resins specifically for fabricating sclera, submitted to chemical and/or mechanical polishing, before and after accelerated aging.

\section{MATERIAL AND METHODS}

To make the specimens, colorless autopolymerized acrylic resin disks were obtained by using a metal matrix $15 \mathrm{~mm}$ in diameter and $2 \mathrm{~mm}$ thickness (Figure 1), according to Kiat-Amnuay, et al. ${ }^{20}$ (2006) but with some changes in diameter.

These disks were included in the proper flasks for microwave polymerization (STG, VIPI, Pirassununga, SP, Brazil), using type III stone plaster (Gesso-Rio, São Paulo, SP, Brazil) and extra hard packing silicone (Zetalabor, Zhermack, Badia Polesine, Rovigo, Italy) for embedding the molds.

After final setting of the materials, silicone and stone plaster, the flasks were opened and the disks removed (Figure 2). The heat-polymerizing acrylic resins N1, N2 and N3 for artificial eyes (Clássico,

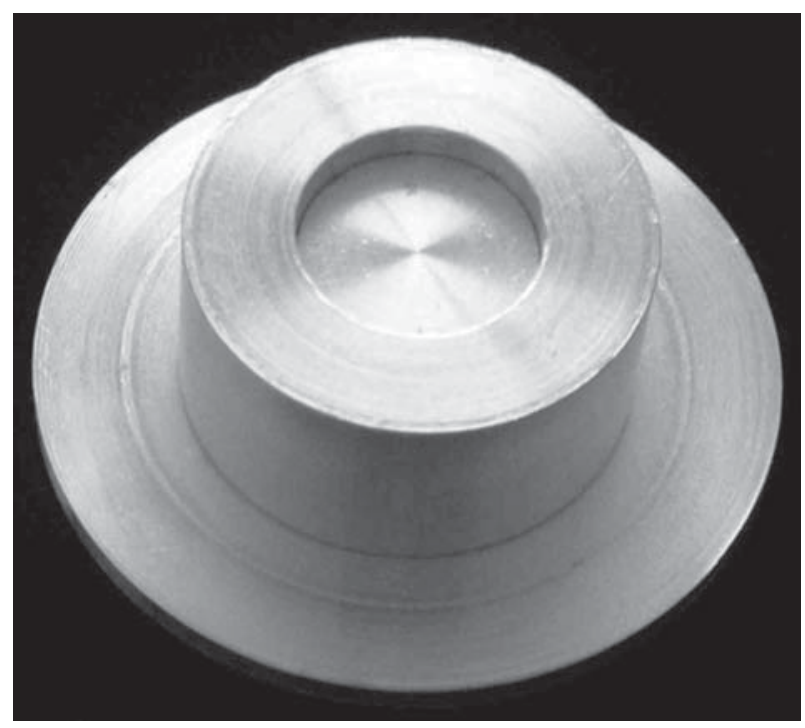

Figure 1- Metallic matrix with 15-mm diameter and 2-mm thickness
Artigos Odontológicos Clássico Ltda., Campo Limpo Paulista, São Paulo, SP, Brazil) were mixed according to the manufacturer's instructions. When the plastic stage was reached, the resins were placed in the molds contained in the flasks and pressed in a hydraulic press (VH, Midas Dental Products Ltda., Araraquara, SP, Brazil) with a force of $1200 \mathrm{KgF}$, and remained at rest for $30 \mathrm{~min}$. After this period, the flasks were taken for microwave polymerization (840 watts) using $60 \%$ of maximum power, for $3 \mathrm{~min}$.

After allowing the flasks to cool naturally, the specimens were deflasked and submitted to finishing for 1 min with abrasive papers no. 280, 320, 600, 1200 (Norton, Norton Abrasivos, Ribeirão Preto, SP, Brazil) and polishing with felt disk and $1 / 4$ micron diamond solution (Buehler, Buehler Ltd, Lake Bluff, IL, USA) in an automatic polisher (Arotec, Cotia, SP, Brazil) at $600 \mathrm{rpm}$.

Of the 14 specimens obtained for each resin, 7 were submitted to mechanical polishing and 7 to chemical polishing 27 .

Chemical polishing was performed in a chemical polishing machine Termotron model PQ-9000 (Termotron, Piracicaba, São Paulo, Brazil) with chemical polishing fluid (Poli-Quim Artigos Odontológicos Clássico Ltda., Campo Limpo Paulista, SP, São Paulo, Brazil). The specimens were immersed in a receptacle containing the fluid at a temperature of $80^{\circ} \mathrm{C}$ for $10 \mathrm{~s}$ (Figure 3). After this period, the specimens were removed from the receptacle and washed under running water according to manufacturer's recommendations after $15 \mathrm{~s}$. The samples were storage in distilled water for $24 \mathrm{~h}$ for reduction of residual monomer ${ }^{17}$. Independent of the activation method, the literature shows the presence of residual monomer ${ }^{17}$.

The alterations in color and brightness were evaluated by reflection spectophotometry (Shimadzu, Shimadzu Corporation, Nakagyo-ku, Kyoto, Japan), as used by Canadas, et al. ${ }^{8}$ (2009)

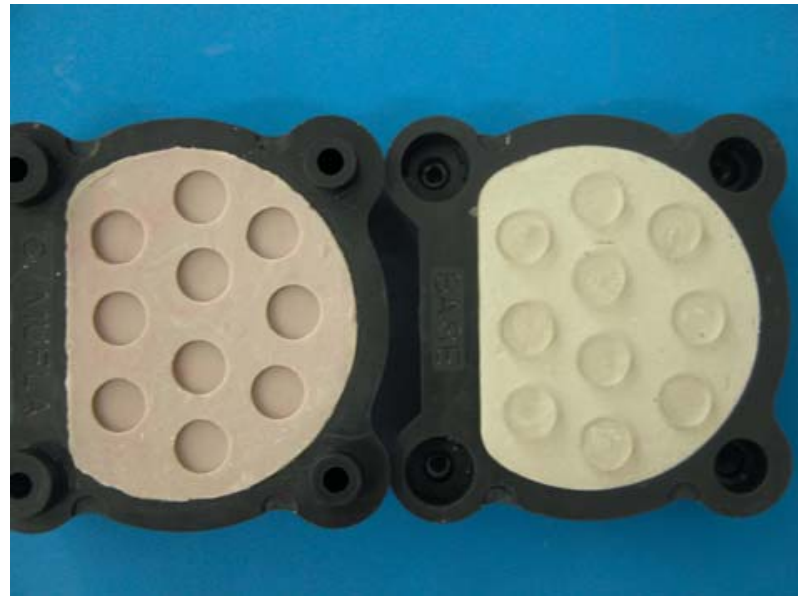

Figure 2- Molds obtained after inclusion of colorless acrylic resin disks in silicone and dental stone 


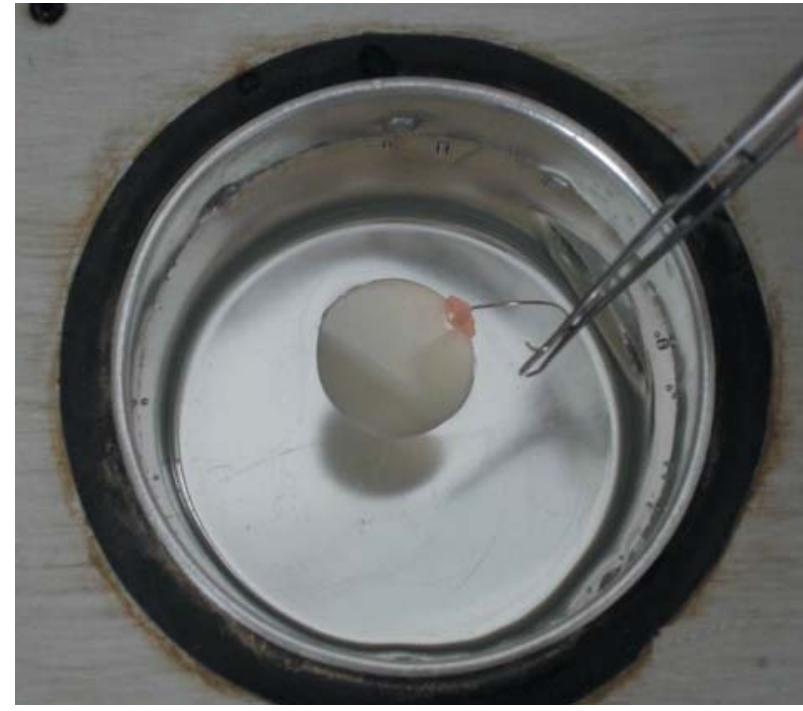

Figure 3- Chemical polishing

and Turner, et al. ${ }^{31}$ (1984) with the alterations in color calculated by the CIELab System.

The CIELab system calculates in the distance between two readings of color through the formula:

$$
\Delta \mathrm{E}=\left[(\Delta \mathrm{L})^{2}+(\Delta \mathrm{a})^{2}+(\Delta \mathrm{b})^{2}\right]^{1 / 2}
$$

After initial chromatic analysis, the specimens were submitted to accelerated aging according to ASTMG 53 Standards (American Society for Testing Materials Standard 53) ${ }^{3}$ in an accelerated aging chamber for nonmetallic bodies - UVB/ condensation (Equilam, Equilam Ind. Co. Ltda., Diadema, SP, Brazil) to simulate extreme environmental conditions. The same operator performed all tests to standardize the testing conditions.

The readings of chromatic stability were performed initially and following the periods of 252,504 , and $1008 \mathrm{~h}$ of accelerated aging. The specimens were cleaned with water and soap before each reading. The results were submitted to ANOVA followed by the Tukey's test at $1 \%$ significance level.

\section{RESULTS}

Table 1 displays the color change values $(\Delta E)$ of the acrylic resins after both polishing procedure and accelerated aging. The N1 acrylic resin presented the lowest $\Delta E$ values that were clinically acceptable by visual analysis of color change.

According to Tukey Kramer test, there was a statistical significant difference on color stability among N1, N2 and N3 resins $(p<0.01)$ regardless of accelerated aging and polishing procedures. The $\mathrm{N} 1$ acrylic resin exhibited the greatest color stability $(\Delta \mathrm{E}=10.74)$, while $\mathrm{N} 3$ acrylic resin exhibited the worst color stability $(\Delta E=13.97)$, with statistically significant difference between them $(p<0.01)$ (Table 2).
Considering the evaluation of color stability among the different periods of accelerated aging, there was significant difference only between 252 and $1008 \mathrm{~h}(\mathrm{p}<0.01)$, independent to the acrylic resin and polishing procedures. The period of 504 $\mathrm{h}(\Delta \mathrm{E}=12.26)$ did not differ in relation to the other periods (Table 3). There was no significant difference between the two types of polishing procedures, regardless of acrylic resin and accelerated aging $(p>0.01)$ (Table 4).

Table 1- Mean values of color derivatives $(\Delta E)$ of resins regarding polishing methods

\begin{tabular}{lccc}
\hline Polishing/Resins & N1 & N2 & N3 \\
\hline 252 hours & & & \\
Mechanical & 10.20 & $12.00^{*}$ & $12.43^{*}$ \\
Chemical & 10.09 & $11.74^{*}$ & $13.03^{*}$ \\
\hline 504 hours & & & \\
Mechanical & 10.75 & $12.41^{*}$ & $13.53^{*}$ \\
Chemical & 10.89 & $11.97^{*}$ & $14.00^{*}$ \\
1008 hours & & & \\
Mechanical & 11.00 & $13.17^{*}$ & $15.47^{*}$ \\
Chemical & 11.54 & $11.86^{*}$ & $15.37^{*}$ \\
\hline
\end{tabular}

${ }^{*} \Delta \mathrm{E} \geq 11.74$ Clinically unacceptable.

Table 2- Mean values of the color derivatives $(\Delta E)$ of resins N1, N2 and N3

\begin{tabular}{lccc}
\hline Material & N1 & N2 & N3 \\
\hline & & & \\
Mean Values & $10.74 \mathrm{~A}$ & $12.19 \mathrm{~B}$ & $13.97 \mathrm{C}$ \\
\hline
\end{tabular}

Means followed by the same capital letter do not differ statistically among them $(p<0.01)$.

Table 3- Mean values of the color derivatives $(\Delta \mathrm{E})$ of different periods of accelerated aging

\begin{tabular}{lrcc}
\hline Accelerated aging & $\mathbf{2 5 2}$ & $\mathbf{5 0 4}$ & $\mathbf{1 0 0 8}$ \\
\hline & & & \\
Mean Values & $11.58 \mathrm{~A}$ & $12.26 \mathrm{AB}$ & $13.07 \mathrm{~B}$ \\
\hline
\end{tabular}

Means followed by the same capital letter do not differ statistically among them $(p<0.01)$.

Table 4- Mean values of the color derivatives $(\Delta \mathrm{E})$ of the two polishing techniques

\begin{tabular}{lcc}
\hline Polishing & Mechanical & Chemical \\
\hline & & \\
Mean Values & $12.33 \mathrm{~A}$ & $12.27 \mathrm{~A}$ \\
\hline
\end{tabular}

Means followed by the same capital letter do not differ statistically between them $(p<0.01)$. 


\section{DISCUSSION}

When analyzing Table 1 , it could be verified that the derivative of shade $(\Delta \mathrm{E})$ for all specimens during the first reading $(252 \mathrm{~h})$ was higher than zero, indicating color alteration by spectrophotometric analysis. This color alteration could be caused by intrinsic and extrinsic factors ${ }^{33}$. The intrinsic factors involve discoloration of the material itself, with alteration in its matrix ${ }^{34}$. Extrinsic factors, such as absorption and adsorption of stains may also cause discoloration ${ }^{1,28}$. In addition to this, other factors are responsible for color instability, such as: accumulation of stains; water sorption; infiltration; surface roughness; chemical degradation by use; oxidation during double-carbon reactions, producing peroxide compounds; and continuous formation of pigments due to degradation of products ${ }^{4,20}$.

There is a great deal of disagreement in the literature about establishing a clinically unsatisfactory value for color derivation. Some authors established $3.5^{21}$ as an unsatisfactory value while other researches stated $3.7^{19}$. In present study, we observed that only color derivatives greater than or equal to 11.74 presented visual alteration (Table 1 ). This makes values below 11.74 satisfactory. In view of this, it appears that there is no way of establishing a universal value clinically unacceptable for $\Delta \mathrm{E}$, since each material has particular physical and chemical properties, and behaves in a different manner, depending on the medium in which it is found.

Significant difference was observed among the $\Delta E$ values of resins $N 1, N 2$ and $N 3$, the highest values of variation being for resin N3 (Table 2). This difference in color derivation could be cause of intrinsic pigmentation of each resin. It is known that the coloring of these resins is achieved by the addition of methylmethacrylate based pigments, which could have participated in polymerization reaction, interfering in formation of polymeric chains, physically or chemically altering the properties of the material ${ }^{27}$. With altered polymeric chains, higher influence of accelerated aging on these materials could have occurred, particularly in resin N3 (Table 1), which presented the highest color alteration values.

In this study, accelerated artificial aging produced significant color alteration in studied resins between 252 and $1008 \mathrm{~h}$ (Table 3). In results it was verified that use of ultraviolet light, humidity and heat were causative factors of polymer degradation. This could occur because the majority of polymers have functional groups in their molecular chains, which absorb ultraviolet light; among them are the carbonyl $\mathrm{C}=\mathrm{O}$ group, aromatic rings, and $\mathrm{C}=\mathrm{C}$ bonds. When a polymer molecule absorbs ultraviolet light through functional groups, this energy leads to a more unstable state of the structure ${ }^{5}$. This excess of energy can be deactivated by various paths, such as transferring the excitation to another molecule, and thus reestablishing itself. These groups can return to their original state by stages, reemitting the excess of energy in a longer wavelength, such as visible light or heat. If the excited molecule disperses the excess of energy by some means, there would be rupture, that is, photochemical degradation, and these factors contribute concomitantly to the appearance of deterioration, such as loss of color or brightness, loss of opacity, appearance of cracks and stiffness ${ }^{5}$.

Regarding to the polishing method, it was verified that the acrylic resin specimens submitted to mechanical and chemical polishing presented no significant difference in the chromatic stability values (Table 4). This appears to indicate that the polishing method used had no influence on the color stability of the test specimens, not even after accelerated aging. Therefore, chemical polishing was performed without a detrimental effect to the physical and chemical properties of the acrylic resins $^{18,26}$

Pinto, et al. ${ }^{24}$ (2001) verified surface roughness in acrylic resins submitted to mechanical and chemical polishing followed by mechanical brushing. This result may contraindicate the chemical burnishing for ocular prosthesis since roughness promotes the accumulation of microorganism. Another alternative would be performing chemical burnishing in short intervals. Radfort, et al. ${ }^{25}$ (1998), Taylor, et al. ${ }^{30}$ (1998), Gonçalves, et al. ${ }^{17}$ (2008) and Bollen, et al. ${ }^{7}$ (1997) emphasized the importance of this point, as the roughness of a denture fitting surface can help determine its colonization by different microorganisms. The importance of the disinfection of ocular prostheses is to decrease the number of microorganisms before and after using cleansing solutions ${ }^{22}$.

Yilmaz, et al. ${ }^{35}$ (2003) cited the ISO 1567, which established that $4.5 \%$ would be an acceptable limit for residual monomer for this kind of resin. Gonçalves, et al. ${ }^{17}$ (2008) verified that the amount of residual monomer after $24 \mathrm{~h}$ of storage reduced from $5.47 \%$ to $3.84 \%$, which is a value considered as biocompatible to tissues. Additional studies are necessary to confirm the long-term behavior of chromatic stability after both polishing techniques.

\section{CONCLUSIONS}

It can be concluded that the N1 acrylic resin displayed the greatest color stability both by visual analysis and by spectrophotometric analysis when compared to the other resins. The accelerated aging by ultraviolet radiation and water condensation influenced significantly the color change of the 
ocular acrylic resins while the polishing technique did not affect the color stability of these resins.

\section{ACKNOWLEDGEMENTS}

The authors would like to thank PIBIC/CNPq (Brazil) for the financial support granted to the project.

\section{REFERENCES}

1- Abu-Bakr N, Han L, Okamoto A, Iwaku M. Color stability of compomer after immersion in various media. J Esthet Dent. 2000;12:258-63.

2- American Dental Association. ANSI/ADA Specification 33: Dental product standards development vocabulary. ANSI/ADA: Chicago; 1984.

3- American Society for Testing Materials Standard. Various standards for Glow Discharge Spectrometry (GDS). [online]. [cited 2008 Nov 27]. Available from: <http://storkview.storksmt.com/ specsite/newspecdetail.asp?topic=ASTM_G154(G53)\&sid=320>. 4- Anil N, Hekimoglu C, Sahin S. Color stability of heat-polymerized and autopolymerized soft denture liners. J Prosthet Dent. 1999;81:481-4.

5- Anusavice KJ. Phillips' science of dental materials. $11^{\text {th }}$ ed. St Louis: Elsevier; 2003.

6- Bagheri R, Burrow MF, Tyas M. Influence of food-simulating solutions and surface finish on susceptibility to staining of aesthetic restorative materials. J Dent. 2005;33:389-98.

7- Bollen CML, Lambrechts P, Quirynen M. Comparison of oral hard materials to the threshold surface roughness for bacterial plaque retention: a review of the literature. Dent Mat. 1997;13:258-69. 8- Canadas MD, Garcia LF, Consani S, Pires-de-Souza FC. Color stability, surface roughness, and surface porosity of acrylic resins for eye sclera polymerized by different heat sources. J Prosthodont. 2010;19:52-7.

9- Erpf SF. Comparative features of plastic and/or glass in artificialeye construction. AMA Arch Ophthalmol. 1953;50:737-44.

10- Fernandes AUR, Goiato MC, Batista MAJ, Santos DM. Color alteration in paint the irises for ocular prostheses. Braz Oral Res. 2009;23:386-92.

11- Fernandes AUR, Goiato MC, Dos Santos DM. Effect of weathering and thickness on roughness of acrylic resin and ocular button. Cont Lens Anterior Eye. 2010;33:124-7.

12- Fernandes AUR, Goiato MC, Dos Santos DM. Effect of weathering and thickness on the superficial microhardness of acrylic resin and ocular button. Cont Lens Anterior Eye. 2009;32:283-7.

13- Goiato MC, Dos Santos DM, Barão VAR, Souza JF, Pesqueira $A A$, Fernandes AUR. Influence of the enclosure, polishing and period of storage, on the roughness of acrylic resins for ocular prosthesis. Cienc Odontol Bras. 2007;10:40-6.

14- Goiato MC, Dos Santos DM, Gennari-Filho H, Zavanelli AC, Dekon SF, Mancuso DN. Influence of investment, disinfection, and storage on the microhardness of ocular resins. J Prosthodont. 2009;18:32-5.

15- Goiato MC, Mancuso DN, Sundefeld MLMM, Gabriel MBM, Murakawa AC, Guiotti AM. Aesthetic and functional ocular rehabilitation. Oral Oncology Extra. 2005;41:162-4.
16- Goiato MC, Pesqueira AA, Ramos da Silva C, Gennari Filho $\mathrm{H}$, Micheline Dos Santos D. Patient satisfaction with maxillofacial prosthesis. Literature review. J Plast Reconstr Aesthet Surg. 2009;62:175-80.

17- Gonçalves TS, Menezes LM, Silva LE. Residual monomer of autopolymerized acrylic resin according to different manipulation and polishing methods. Angle Orthod. 2008;78:722-7.

18- Gotusso MJ. Sorption of heat-cured acrylic resins chemically polished. J Dent Res. 1969;48:1072-8.

19- Johnston WM, Kao EC. Assessment of appearance match by visual observation clinical colorimetry. J Dent Res. 1989;68:81922.

20- Kiat-Amnuay S, Mekayarajjananonth K, Powers JM, Chambers MS, Lemon JC. Interactions of pigments and opacifiers on color stability of MDX4-4210/type A maxillofacial elastomers subjected to artificial accelerated aging. J Prosthet Dent. 2006;95:249-57. 21- O'Brien WJ. Dental materials and their selection. $2^{\text {nd }}$ ed. Chicago: Quintessence; 1997. p.115-22.

22- Paranhos RM, Batalhão $\mathrm{CH}$, Semprini M, Regalo SC, Ito IY, Mattos MG. Evaluation of ocular prosthesis biofilm and anophthalmic cavity contamination after use of three cleansing solutions. J Appl Oral Sci. 2007;15:33-8.

23- Patil SB, Meshramkar R, Naveen BH, Patil NP. Ocular prosthesis: a brief review and fabrication of an ocular prosthesis for a geriatric patient. Gerodontology. 2008;25:57-62.

24- Pinto JRR, Mochizuki MY, Tursi CP, Henriques GEP, Domitti SS, Mesquita MF. Influence of brushing in maintenance of polish in complete denture's bases. In: Annual Meeting of the Brazilian Society for Dental Research. J Dent Res. 2001;80:1047.

25- Radford DR, Sweet SP, Challacombe SJ, Walter JD. Adherence of Candida albicans to denture-base materials with different surface finishes. J Dent. 1998;26:577-83.

26- Rahal JS, Mesquita MF, Henriques GE, Nóbilo MA. Influence of chemical and mechanical polishing on water sorption and solubility of denture base acrylic resins. Braz Dent J. 2004;15:225-30.

27- Rahal JS, Mesquita MF, Henriques GE, Nóbilo MA. Surface roughness of acrylic resins submitted to mechanical and chemical polishing. J Oral Rehabil. 2004;31:1075-9.

28- Satou N, Khan AM, Matsumae I, Satou J, Shintani H. In vitro color change of composite-based resins. Dent Mater. 1989;5:3847.

29- Stewart RE. Plastic artificial eye and restorations program, Veterans Administration. Milit Surg. 1947;101:396-404.

30- Taylor R, Maryan C, Verran J. Retention of oral microorganisms on cobalt-chromium alloy and dental acrylic resin with different surface finishes. J Prosthet Dent. 1998;80:592-7.

31- Turner GE, Fischer TE, Castleberry DJ, Lemons JE. Intrinsic color of isophorone polyurethane for maxillofacial prosthetics. Part II: Color stability. J Prosthet Dent. 1984;51:673-5.

32- Ulusoy M, Ulusoy N, Aydin AK. An evaluation of polishing techniques on surface roughness of acrylic resins. J Prosthet Dent. 1986;56:107-12.

33- Villalta P, Lu H, Okte Z, Garcia-Godoy F, Powers JM. Effects of staining and bleaching on color change of dental composite resins. J Prosthet Dent. 2006;95:137-42.

34- Wilson NH, Burke FJ, Mjör JA. Reasons for placement and replacement of restorations of direct restorative materials by a selected group of practitioners in the United Kingdom. Quintessence Int. 1997;28:245-8.

35- Yilmaz H, Aydin C, Cağlar A, Yaşar A. The effect of glass fiber reinforcement on the residual monomer content of two denture base resins. Quintessence Int. 2003;34:148-53. 